\title{
X-ray Structural Investigation of Nonsymmetrically and Symmetrically Alkylated [1]Benzothieno[3,2-b]benzothiophene Derivatives in Bulk and Thin Films
}

\author{
Gabin Gbabode, ${ }^{*}, \dagger, \perp$ Michael Dohr, ${ }^{\S}$ Claude Niebel, ${ }^{\ddagger}$ Jean-Yves Balandier, ${ }^{\ddagger}$ Christian Ruzié, ${ }^{\ddagger}$ \\ Philippe Négrier," Denise Mondieig, "Yves H. Geerts, ${ }^{\ddagger}$ Roland Resel, ${ }^{\S}$ and Michele Sferrazza ${ }^{\dagger}$ \\ ${ }^{\dagger}$ Département de Physique, Faculté des Sciences, and ${ }^{\ddagger}$ Laboratoire de Chimie des Polymères, Faculté des Sciences, Université libre de \\ Bruxelles (ULB), Boulevard du Triomphe, 1050 Brussels, Belgium \\ ${ }^{\S}$ Institute of Solid State Physics, Graz University of Technology, Petersgasse 16, 8010 Graz, Austria \\ "Université de Bordeaux, LOMA, UMR 5798, 351 cours de la Libération, 33400 Talence, France
}

\begin{abstract}
A detailed structural study of the bulk and thin film phases observed for two potential high performance organic semi conductors has been carried out. The molecules are based on [1] benzothieno[3,2 $b$ ] benzothiophene (BTBT) as conjugated core and octyl side groups, which are anchored either symmetrically at both sides of the BTBT core $\left(\mathrm{C}_{8}-\mathrm{BTBT}-\mathrm{C}_{8}\right)$ or nonsymmetrically at one side only $\left(\mathrm{C}_{8}-\mathrm{BTBT}\right)$. Thin films of different thickness $(8-85 \mathrm{~nm})$ have been prepared by spin coating for both systems and analyzed by combining specular and grazing incidence $\mathrm{X}$ ray diffraction. In the case of $\mathrm{C}_{8}-\mathrm{BTBT}-\mathrm{C}_{8}$, the known crystal structure obtained from single crystal investigations is observed within all thin films, down to a film thickness of $9 \mathrm{~nm}$. In the case of $\mathrm{C}_{8}$ -BTBT, the crystal structure of the bulk phase has been determined from $\mathrm{X}$ ray powder diffraction data with a consistent matching of experimental and calculated $\mathrm{X}$ ray diffraction patterns ( $\mathrm{Rwp}=5.8 \%$ ).

The packing arrangement of $\mathrm{C}_{8}-\mathrm{BTBT}$ is similar to that of $\mathrm{C}_{8}-\mathrm{BTBT}-\mathrm{C}_{8}$, that is, consisting of a lamellar structure with molecules arranged in a "herringbone" fashion, yet with lamellae composed of two head to head (or tail to tail as the structure is periodic) superimposed molecules instead of only one molecule for $\mathrm{C}_{8}-\mathrm{BTBT}-\mathrm{C}_{8}$. As for $\mathrm{C}_{8}-\mathrm{BTBT}-\mathrm{C}_{8}$, w e demonstrate that the same phase is observed in bulk and thin films for $\mathrm{C}_{8}-\mathrm{BTBT}$ whatever the film thickness investigated.

KEYWORDS: $X$ ray diffraction, organic thin films, substrate induced phase, organic electronics, polymorphism
\end{abstract}

\section{INTRODUCTION}

In the past decades, particular attention has been paid to organic molecules comprising $\pi$ conjugated moieties due to their potential applications in the promising field of organic electronics. $^{1-5}$ In this framework, knowledge of the crystal packing of target molecules is of prime importance because charge transport properties are highly dependent on the structural arrangement exhibited. ${ }^{6-8}$ Furthermore, it has been demonstrated that charge transport is effectively driven by the first molecular layers close to the underlying substrate in the case of organic field effect transistors (OFETs). ${ }^{9}$ Structural characterization studies aiming at seeking eventual poly morphism in thin films and understanding its occurrence are mandatory for a rational design of devices architecture. ${ }^{10}$

The existence of a structural organization observed only in thin films and that is different from that observed in the bulk (the so called "thin film phase") was first observed for vapor deposited pentacene thin films on silicon substrate. ${ }^{11,12}$ Subsequently, numerous studies have been undertaken to investigate the crystal structure ${ }^{13-17}$ and the origin ${ }^{18-23}$ of these thin film phases considering the high relevance of pentacene for thin film organic electronic applications. ${ }^{2-4}$ Surface energy ${ }^{18,19}$ and structure, ${ }^{20,21}$ substrate roughness, ${ }^{22,23}$ as well as processing conditions ${ }^{24-26}$ have been reported to play a role in the preferential crystallization of a given structural organization close to the substrate. Remarkably, recent theoretical studies based on Molecular Dynamics (MD) simulations ${ }^{20-23}$ brought significant insight on the influence of substrate/molecules and molecules/molecules interactions on polymorph selection close to the substrate-molecule interface. In particular, Yoneya et al. $^{22}$ showed that, even if the substrate induced phase of pentacene is energetically less favorable than the bulk phase (as was also proved by Della Valle and co workers in a previous study ${ }^{20}$ ), it is however stabilized 
close to the silicon substrate because its crystal structure presents a flatter interface between molecular lamellae, which matches more closely the flat surface of the silicon oxide substrate. The work of Bredas et al. ${ }^{21}$ is also worth mentioning as it raises a direct relationship between the electrostatic force induced by the silicon oxide surface on nearby pentacene molecules and the change of molecular packing, that is, in other words, the influence of surface structure of the substrate (silicon and oxygen contents in this example) on the stabilization of different crystal structure close to the substrate surface (now commonly called "substrate induced phases or polymorphs").

Since the early works on pentacene, numerous studies have been reporting the presence of substrate induced phases for other more complex molecules than pentacene. ${ }^{24-30}$ The question may arise whether or not the reasons for the stabilization of substrate phases enounced in the case of the model compound pentacene would also be applied for these compounds.

In an attempt to propose an answer for this interrogation, we consider, herein, two different molecules both composed of a central [1]benzothieno[3,2 b] benzothiophene (BTBT) core substituted either: (a) symmetrically by octyl chains at both ends of the BTBT core $\left(\mathrm{C}_{8}-\mathrm{BTBT}-\mathrm{C}_{8}\right)$ or $(\mathrm{b})$ nonsymmetri cally by a single octyl chain at one side of the BTBT core $\left(\mathrm{C}_{8}-\right.$ BTBT). Alkylated BTBT molecules are currently among the most promising candidates to be used as solution processed air stable high performance organic semiconductors. ${ }^{31-36}$ Average charge transport mobilities as high as $16.4 \mathrm{~cm}^{2} /(\mathrm{V} \mathrm{s})$ on single crystals ${ }^{34}$ and $3.5 \mathrm{~cm}^{2} /(\mathrm{V} \mathrm{s})$ on polycrystalline thin films ${ }^{33}$ have been reported for the dialkylated derivatives. Furthermore, more recently, record maximum and average hole mobilities of 17.2 and $14.2 \mathrm{~cm}^{2} /(\mathrm{V} \mathrm{s})$, respectively, have been obtained by the group of Halik on evaporated thin films of the monoalkylated $\mathrm{C}_{13}-\mathrm{BTBT}$ integrated in OFETs with opti mized contacts between the dielectric and the organic semiconductor layers. ${ }^{35,36}$ The high charge mobility is explained by the authors as being related to the reduction of insulating areas between the semiconducting conjugated BTBT cores due to the presence of only one alkyl chain in the molecule. Furthermore, the authors proved the existence of a dense packing of the BTBT cores close to the substrate characterized by a small repeating distance of 13-14 Å between them (much smaller than the length of the molecule, which is around $24 \AA$ ) perpendicularly to the substrate surface as revealed by $\mathrm{X}$ ray reflectivity measurements.

The bulk crystal structure of $\mathrm{C}_{8}-\mathrm{BTBT}-\mathrm{C}_{8}$ has previously been solved by Takimiya et al. ${ }^{31,32}$ Moreover, the same authors also investigated the molecular packing of spin coated thin films of $\mathrm{C}_{8}-\mathrm{BTBT}-\mathrm{C}_{8}$ by $\mathrm{X}$ ray diffraction and conclude on the same molecular packing in the bulk material as in thin films. However, film thickness was not specified nor varied in this study. The phase behavior of $\mathrm{C}_{8}-\mathrm{BTBT}$ is more complicated because of the presence of at least two polymorphs as has been shown in a previous publication. ${ }^{37}$ Unit cell parameters have been proposed for the two crystalline modifications from $\mathrm{X}$ ray diffraction measurements on extruded fibers, ${ }^{37}$ but these results have not been confirmed by crystal structure resolution. To the best of our knowledge, nothing is known on the phase behavior of $\mathrm{C}_{8}-\mathrm{BTBT}$ in thin films.

In this Article, we will investigate the solid state arrangement of $\mathrm{C}_{8}-\mathrm{BTBT}-\mathrm{C}_{8}$ and $\mathrm{C}_{8}-\mathrm{BTBT}$ through structural character ization of powder bulk samples and spin coated thin films of various film thicknesses to probe the existence of substrate induced phases for this family of compounds and try to understand their occurrence or absence.

\section{EXPERIMENTAL SECTION}

Materials. $\mathrm{C}_{8}-\mathrm{BTBT}^{38}$ and $\mathrm{C}_{8}-\mathrm{BTBT}-\mathrm{C}_{8}{ }^{31}$ (shown in Figure 1 ) were prepared following the literature procedure.

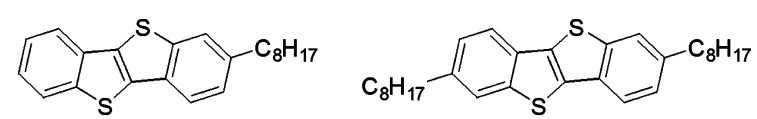

Figure 1. Molecular structures of $\mathrm{C}_{8}-\mathrm{BTBT}$ (left) and $\mathrm{C}_{8}-\mathrm{BTBT}-\mathrm{C}_{8}$ (right).

Thin Film Fabrication. Thin films were prepared by spin coating onto oxidized silicon wafers. Different solvents were used, toluene for $\mathrm{C}_{8}-\mathrm{BTBT}$ and tetrahydrofuran for $\mathrm{C}_{8}-\mathrm{BTBT}-\mathrm{C}_{8}$. Toluene solutions with concentrations of 10,5 , and $2 \mathrm{mg} / \mathrm{mL}$ resulted in film thicknesses of around 30,15, and $8 \mathrm{~nm}$, respectively, using spinning speeds of $2500 \mathrm{rpm}$ for $30 \mathrm{~s}$. Tetrahydrofuran solutions with various concentrations varying from 0.03 to $10 \mathrm{mg} / \mathrm{mL}$ yielded film thicknesses ranging from around $9 \mathrm{~nm}$ to around $85 \mathrm{~nm}$, using spinning speeds of $1000 \mathrm{rpm}$ for $9 \mathrm{~s}$ with subsequent $1500 \mathrm{rpm}$ for 30 s. Film thicknesses were determined by $\mathrm{X}$ ray reflectivity and spectroscopic ellipsometry with an overall accuracy of $\pm 5 \mathrm{~nm}$. Actually, the films produced are relatively rough so that Kiessig fringes could not be observed for most of them in their respective $\mathrm{X}$ ray reflectivity curves. However, for most samples, ellipsometry measurements could allow the determination of the film thicknesses. Hence, the uncertainty given is more related to these measurements. Film thicknesses determined by ellipsometry were in turn validated by $\mathrm{X}$ ray reflectivity measurements when available. Additionally, when thin films were too rough to allow the determination of film thickness by the latter measurements, it was evaluated directly by crystallite size determination (Scherrer's equation) with the assumption that crystal domains extend through the whole film thickness, which is quite reasonable for such highly polycrystalline thin films.

X-ray Diffraction (XRD) Measurements. Crystal Structure Determination from $X$-ray Powder Data $\left(C_{8}-B T B T\right)$. High quality powder diffraction patterns were obtained using an Inel CPS $120 \mathrm{X}$ ray powder diffractometer equipped with an Oxford Cryosystems $\mathrm{N}_{2}$ cryostream heating device. Inel CPS 120 works in a typical DebyeScherrer transmission geometry $\left(\mathrm{Cu} \mathrm{K} \alpha_{1}\right.$ radiation, $\lambda=0.15406 \mathrm{~nm}$, as incident beam) where diffracted rays are simultaneously collected on a $120^{\circ}$ position sensitive curved counter by gas ionization (argon + $\mathrm{C}_{2} \mathrm{H}_{6}$ ). Samples are introduced into $0.5 \mathrm{~mm}$ diameter Lindemann glass capillaries, which are rotated around their axis during the experiment to minimize preferential orientation of crystallites. External calibration to convert the measured 4096 channels to $2 \theta$ degrees was applied using cubic $\mathrm{Na}_{2} \mathrm{Ca}_{2} \mathrm{Al}_{2} \mathrm{~F}_{4}$ (high angle calibration) ${ }^{39}$ mixed with silver behenate (low angle calibration). ${ }^{40}$ The time of acquisition was set to $17 \mathrm{~h}$ to obtain reflections with exploitable intensities.

The crystal structure determination procedure was performed using programs implemented in the Reflex Plus module of Material Studio software. ${ }^{41}$ First, lattice constants and space group were determined using X Cell software ${ }^{42}$ starting from a set of 33 reflections with $2 \theta<$ $28^{\circ}$. Cell parameters together with peak profile parameters (shape, Pseudo Voigt function, asymmetry, and full width at half maximum), background, and zero shift were subsequently refined by Pawley refinement. ${ }^{43}$ Crystal structure determination was achieved using a rigid body simulated annealing procedure using PowderSolve program. ${ }^{44}$ The geometry of the starting $\mathrm{C}_{8}-\mathrm{BTBT}$ molecule was optimized using DREIDING force field. ${ }^{45}$ Moreover, the dihedral angle around the $\mathrm{C}-\mathrm{C}$ bond connecting the octyl chain to the BTBT core was allowed to vary in the simulated annealing procedure (together with the three translations and three rotations of the rigid geometry optimized $\mathrm{C}_{8}-\mathrm{BTBT}$ molecule) as it is observed in the crystal structure of dialkylated BTBTs that the planes containing the 
Table 1. Summary of the Experimental Conditions Employed for the Various X ray Diffraction Measurements Performed on $\mathrm{C}_{8}-\mathrm{BTBT}$ and $\mathrm{C}_{8}-\mathrm{BTBT}-\mathrm{C}_{8}$

\begin{tabular}{|c|c|c|c|c|c|c|}
\hline & & apparatus designation & configuration & source & detector & $\begin{array}{l}\text { wavelength } \\
(\mathrm{nm})\end{array}$ \\
\hline \multirow[t]{3}{*}{$\mathrm{C}_{8}$ ВTBT } & crystal structure determination & Inel CPS 120 & transmission & laboratory & linear & 0.15406 \\
\hline & sXRD & Bruker D8 Advance & reflection $(\theta / \theta)$ & laboratory & point & 0.15418 \\
\hline & GIXD & Rigaku Smartlab & grazing incidence $\left(\alpha_{\mathrm{i}}=0.2^{\circ}\right)$ & laboratory & point & 0.15418 \\
\hline \multirow[t]{3}{*}{$\mathrm{C}_{8}$ BTBT $\mathrm{C}_{8}$} & crystal structure determination & & & & & \\
\hline & sXRD & Panalytical Empyrean System & reflection $(\theta / \theta)$ & laboratory & point & 0.15418 \\
\hline & GIXD & W1 beamline (HASYLAB) & grazing incidence $\left(\alpha_{\mathrm{i}}=0.15^{\circ}\right)$ & synchrotron & linear & 0.11801 \\
\hline
\end{tabular}

a)

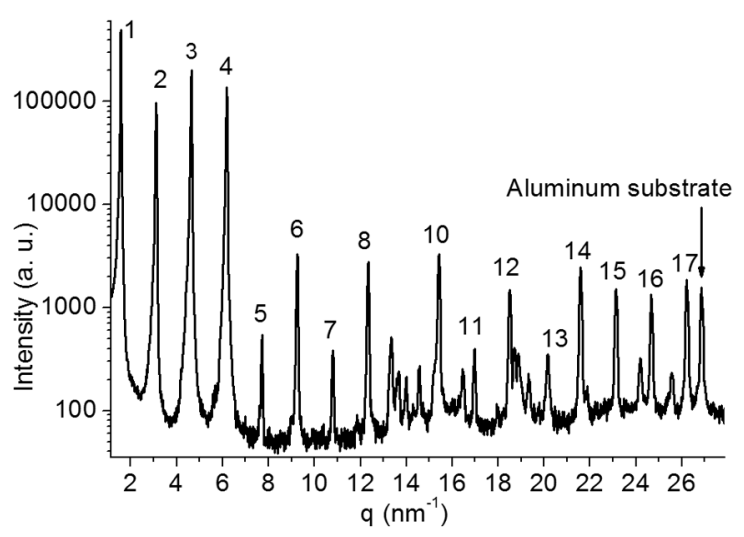

b)

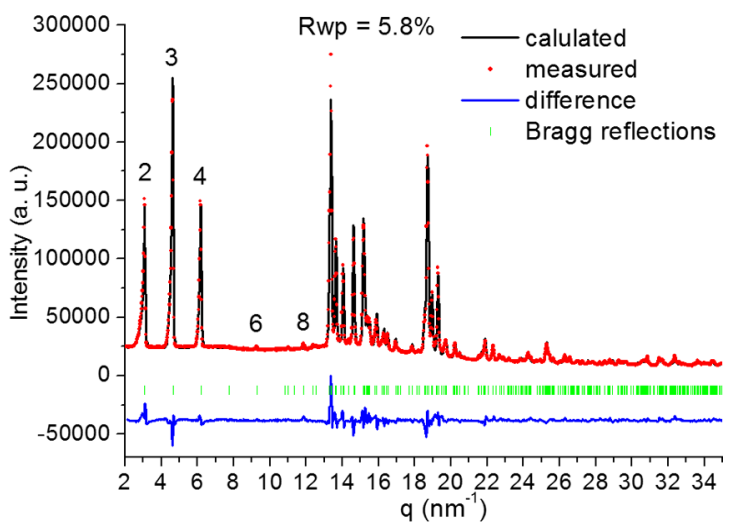

c)

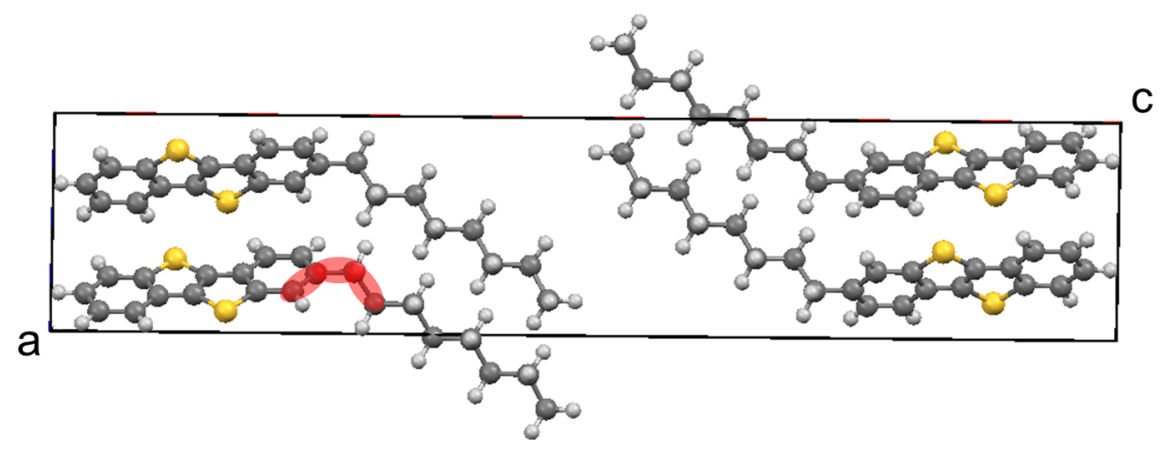

Figure 2. (a) $s X R D$ pattern of a $\mathrm{C}_{8}-\mathrm{BTBT}$ powder sample measured at room temperature (form III). The numbers correspond to the diffraction order of the reflections originated from the lamellar stacking (001 reflections). (b) Rietveld fit of an X ray powder diffraction pattern of form III measured in transmission geometry. Red dots, black line, blue line, and green bars correspond to experimental data, calculated data, difference between both, and calculated positions of Bragg reflections, respectively. Note the drastic intensity decrease of 001 reflections as compared to the other Bragg reflections, emphasizing much reduced 001 texture as compared to the $\mathrm{X}$ ray diagram shown in (a). (c) Packing arrangement of $\mathrm{C}_{8}-$ BTBT molecules within the crystallographic $P 2_{1} / a$ unit cell represented along the $b$ axis (the four red shaded carbon atoms correspond to those taken into account to measure the $\mathrm{C}-\mathrm{C}-\mathrm{C}-\mathrm{C}$ torsion angle given in Table 2 ).

zigzag of the alkyl chains and the plane of the BTBT moiety are not parallel. $^{31,32}$ The final crystal structure was then obtained after Rietveld refinement of the best crystal structure attained from the simulated annealing procedure (low $R_{\text {wp }}$ factor and realistic intermolecular interactions), encompassing refinement of the seven degrees of liberty of the rigid body (translations, rotations, and torsion angle), an isotropic mean temperature factor, and parameters describing preferential orientation of crystallites.

Specular X-ray Diffraction. Specular X ray diffraction (sXRD) experiments were performed on powder samples (gently crushed powder subsequently spread on the diffractometer flat sample holder) and thin films. In the former case, all $h k l$ reflections can be observed allowing, in particular, unit cell determination, while in the latter case pronounced preferential orientation of crystallites markedly reduces the number of $h k l$ reflections observed. It is commonly said that sXRD measurements reveal the "out of plane" structure of thin films. A
Bruker D8 Advance $\left(\mathrm{C}_{8}-\mathrm{BTBT}\right)$ and a Panalytical Empyrean system $\left(\mathrm{C}_{8}-\mathrm{BTBT}-\mathrm{C}_{8}\right)$ laboratory diffractometers were used, which both work in $\theta / \theta$ reflection geometry with $\mathrm{Cu} \mathrm{K}_{\alpha}$ radiation $(\lambda=0.15418$ $\mathrm{nm})$ as incident beam and a typical angular resolution of $0.02^{\circ}$.

Grazing Incidence X-ray Diffraction. Grazing incidence $\mathrm{X}$ ray diffraction (GIXD) measurements were performed either in house on a Rigaku Ultima IV diffractometer $\left(\mathrm{C}_{8}-\mathrm{BTBT}\right.$ thin films) or at W1 beamline of HASYLAB, Hamburg, Germany $\left(\mathrm{C}_{8}-\mathrm{BTBT}-\mathrm{C}_{8}\right.$ thin films). In the former case, the incoming parallel $\mathrm{X}$ ray beam $\left(\mathrm{Cu} \mathrm{K} \mathrm{K}_{\alpha}\right.$ radiation) was set at an incidence angle $\alpha_{\mathrm{i}}$ of $0.2^{\circ}$, that is, less than the critical angle of total reflection of the silicon substrate, and the detector at an outgoing angle $\alpha_{\mathrm{f}}$ of $0.2^{\circ}$. The lateral divergence of the incident and diffracted beams is maintained at $0.5^{\circ}$ due to two Soller slits sets placed before and after the sample. The detector moves in a direction perpendicular to the reflection plane making an angle $2 \theta_{\chi}$ with the direct beam (typical speed and angular resolution: $0.1^{\circ} / \mathrm{min}$ and $0.02^{\circ}$, 
respectively), while the sample rotates around the axis perpendicular to its normal at an angle $\varphi=2 \theta_{\chi} / 2\left(2 \theta_{\chi} / \varphi\right.$ scans $)$. In this configuration, diffracted rays from crystallographic planes essentially perpendicular to the substrate surface are detected, thus giving information on the "in plane" structure of thin films.

The synchrotron measurements have been performed using a wavelength of $\lambda=0.11801 \mathrm{~nm}$. The beam size was tuned by vertical and horizontal mountable slits on the primary side; the incident angle was optimized for the scattered intensity of the organic layer at $0.15^{\circ}$. The secondary side was equipped with an evacuated flight tube and a 1D Mythen position sensitive detector. The latter moves transversally to the reflection plane, allowing the detection of diffracted rays from crystallographic planes perpendicular and also oblique to the sample surface.

Table 1 summarizes the experimental conditions of the different $\mathrm{X}$ ray diffraction measurements performed on the two compounds.

To compare $\mathrm{X}$ ray diffraction measurements collected with different wavelengths, all $\mathrm{X}$ ray diffraction patterns presented throughout this Article will be plotted as a function of the scattering vector $q$ using the relation $q=(4 \pi / \lambda) \sin \theta$ with $\lambda$ the wavelength of the $\mathrm{X}$ rays and $\theta$ the angle of diffraction. In the case of thin films, the components of the scattering vector perpendicular and parallel to the substrate surface are noted $q_{z}$ and $q_{x y}$, respectively.

\section{RESULTS}

Bulk Phase Behavior of $\mathrm{C}_{8}-\mathrm{BTBT}-\mathrm{C}_{8}$ and $\mathrm{C}_{8}-\mathrm{BTBT}$. The bulk phase behavior of $\mathrm{C}_{8}-\mathrm{BTBT}-\mathrm{C}_{8}$ has already been reported by Takimiya and co workers, ${ }^{31}$ and it is as follows: a crystalline phase (stable at room temperature) transforms into a smectic A mesophase at around $112{ }^{\circ} \mathrm{C}$, which then melts at around $127^{\circ} \mathrm{C}$. The crystalline phase is monoclinic with space group $P 2 / a$ and consists of a lamellar arrangement of $\mathrm{C}_{8}-$ $\mathrm{BTBT}-\mathrm{C}_{8}$ molecules with herringbone packing within the lamellae. $^{31,32}$

In the case of $\mathrm{C}_{8}-\mathrm{BTBT}$, the phase sequence as a function of temperature is more complex and involves only crystalline phases: form I, stable at room temperature (present in the crude powder or in samples recrystallized from solution at room temperature), form II, stable at high temperature (obtained either from form I or III upon heating before the melting of $\mathrm{C}_{8}-\mathrm{BTBT}$ ), and form III, metastable at room temperature (kinetically favored upon cooling from the melt or from form II). A detailed description of the bulk phase behavior of $\mathrm{C}_{8}-\mathrm{BTBT}$ is not the intent of this Article and is partly dealt with in another publication. ${ }^{37}$ However, it is worth noting that Form III is reproducibly obtained upon cooling from the liquid phase or from the high temperature form II and is maintained at room temperature upon further heating/cooling cycles. We then chose to consider $\mathrm{C}_{8}-\mathrm{BTBT}$ in form III for powder samples and thin films, by systematically performing a quick annealing at $130{ }^{\circ} \mathrm{C}$ (above the melting temperature) followed by a slow cooling to room temperature (by ambient air). Indeed, by adding this processing step, thermal history of samples is erased, thus ensuring consistent results between different $\mathrm{C}_{8}-\mathrm{BTBT}$ batches.

A representative $s X R D$ pattern of a powder sample of $\mathrm{C}_{8}-$ BTBT form III is shown in Figure 2a. Several correlated reflections (up to at least 17 th order) corresponding to the lamellar packing of $\mathrm{C}_{8}-\mathrm{BTBT}$ molecules are observed. This clearly emphasizes significant crystalline order of annealed $\mathrm{C}_{8}-$ BTBT samples but also strong preferential orientation of crystallites with lamellar planes parallel to the substrate surface. Reflections related to the molecular packing within the lamellae can be observed for $q>13 \mathrm{~nm}^{-1}$ between the lamellar peaks. This sXRD pattern could allow the determination of lattice constants and space group, but crystal structure determination was hampered by the strong preferential orientation of crystallites observed. $\mathrm{X}$ ray diffraction patterns measured in transmission geometry (Inel CPS 120 diffractometer) showed significantly less influence of these effects and readily allowed the determination of the crystal structure of form III. Figure $2 b$ displays the fairly good matching between measured and calculated $\mathrm{X}$ ray diffraction patterns $\left(R_{\mathrm{wp}}=5.8 \%\right)$, while Figure $2 \mathrm{c}$ shows a representation of the molecular packing in the unit cell along $b$ axis and Table 2 displays structural data determined for form III of $\mathrm{C}_{8}-\mathrm{BTBT}$ together with the same corresponding data taken from the crystal structure of $\mathrm{C}_{8}-$ $\mathrm{BTBT}-\mathrm{C}_{8}$.

\begin{tabular}{|c|c|c|}
\hline & $\mathrm{C}_{8} \quad \mathrm{BTBT}$ (Form III) & $\begin{array}{lll}\mathrm{C}_{8} & \mathrm{BTBT} & \mathrm{C}_{8}\end{array}$ \\
\hline$a(\mathrm{~nm})$ & $0.8287(1)$ & $0.5927(7)$ \\
\hline$b(\mathrm{~nm})$ & $0.5756(1)$ & $0.788(1)$ \\
\hline$c(\mathrm{~nm})$ & $4.0567(4)$ & $2.918(4)$ \\
\hline$\beta(\operatorname{deg})$ & $90.63(1)$ & $92.443(4)$ \\
\hline$Z$ & 4 & 4 \\
\hline density $\left(\mathrm{g} / \mathrm{cm}^{3}\right)$ & $1.210(1)$ & $1.133(9)$ \\
\hline space group & $P 2_{1} / a$ & $P 2_{1} / a$ \\
\hline Herringbone angle $^{a}$ (deg) & 64 & 56 \\
\hline C $C$ C C torsion angle ${ }^{b}(\mathrm{deg})$ & 87 & 66 \\
\hline
\end{tabular}

${ }^{a}$ Angle between the planes parallel to the BTBT cores of two neighboring molecules. ${ }^{b}$ See Figure $2 c$.

The crystal structure of $\mathrm{C}_{8}-\mathrm{BTBT}$ form III is monoclinic with space group $P 2_{1} / a$ and $Z=4$ as for the crystalline phase of $\mathrm{C}_{8}-\mathrm{BTBT}-\mathrm{C}_{8}$ (Table 2). The lattice dimensions are also quite similar between the two compounds except that $c$ is much higher for $\mathrm{C}_{8}-\mathrm{BTBT}$. Indeed, both crystal structures consist of a typical lamellar packing of herringbone stacked $\mathrm{C}_{8}-\mathrm{BTBT}$ molecules (herringbone angle is close to $60^{\circ}$ for both structures as shown in Table 2) yet with the noticeable difference that lamellae are composed of bilayers of head to head (or tail to tail as the structure is periodic) packed molecules in the case of $\mathrm{C}_{8}$-BTBT (Figure 2c), while lamellae's height is composed of only one molecule for $\mathrm{C}_{8}-\mathrm{BTBT}-\mathrm{C}_{8}$. Furthermore, it can be noticed that the values of $a$ and $b$ cell parameters are almost exchanged between $\mathrm{C}_{8}-\mathrm{BTBT}$ form III and $\mathrm{C}_{8}-\mathrm{BTBT}-\mathrm{C}_{8}(a$ $\left(\mathrm{C}_{8}-\mathrm{BTBT}\right) \approx b\left(\mathrm{C}_{8}-\mathrm{BTBT}-\mathrm{C}_{8}\right)$ and $b\left(\mathrm{C}_{8}-\mathrm{BTBT}\right) \approx a$ $\left(\mathrm{C}_{8}-\mathrm{BTBT}-\mathrm{C}_{8}\right)$; see Table 2$)$ while keeping the same space group for both crystal structures. This indicates different symmetry related molecules between the two structures in the same crystallographic direction, that is, a slightly different packing arrangement of molecules within the layers. The distinct intralayer molecular packing is also emphasized by the relatively different conformation of octyl chains with respect to the BTBT cores for the two molecules $(\mathrm{C}-\mathrm{C}-\mathrm{C}-\mathrm{C}$ torsion angle of $87^{\circ}$ and $66^{\circ}$ for $\mathrm{C}_{8}-\mathrm{BTBT}$ and $\mathrm{C}_{8}-\mathrm{BTBT}-\mathrm{C}_{8}$, respectively) implying a dissimilar packing arrangement of alkyl chains between the two crystal structures. Finally, these differences result in a substantially denser crystal structure of $\mathrm{C}_{8}-\mathrm{BTBT}$ form III as compared to that of $\mathrm{C}_{8}-\mathrm{BTBT}-\mathrm{C}_{8}$ with calculated crystal densities of $1.210(1) \mathrm{g} / \mathrm{cm}^{3}$ for the former and $1.133(9) \mathrm{g} / \mathrm{cm}^{3}$ for the latter. 
a)

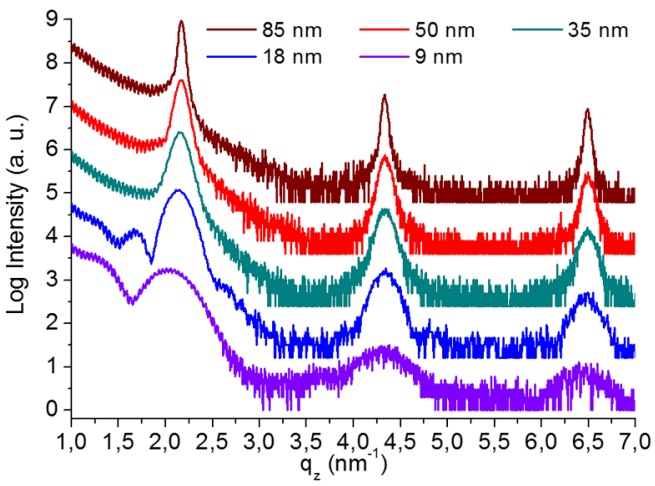

c)

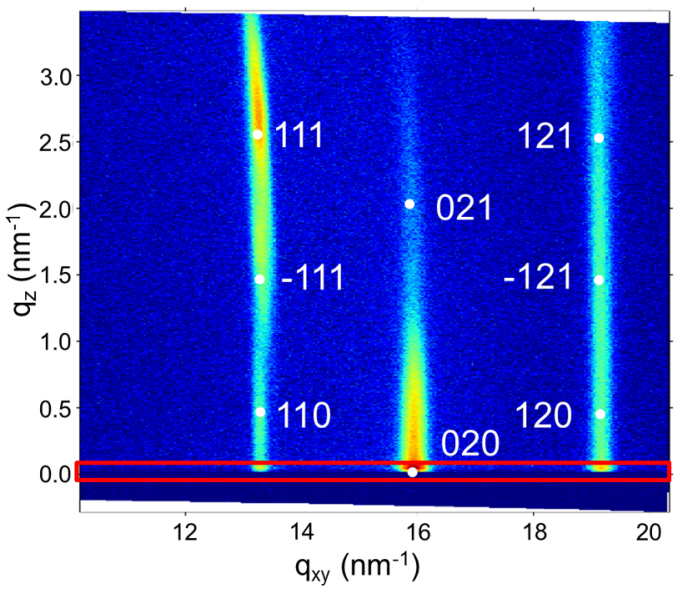

b)

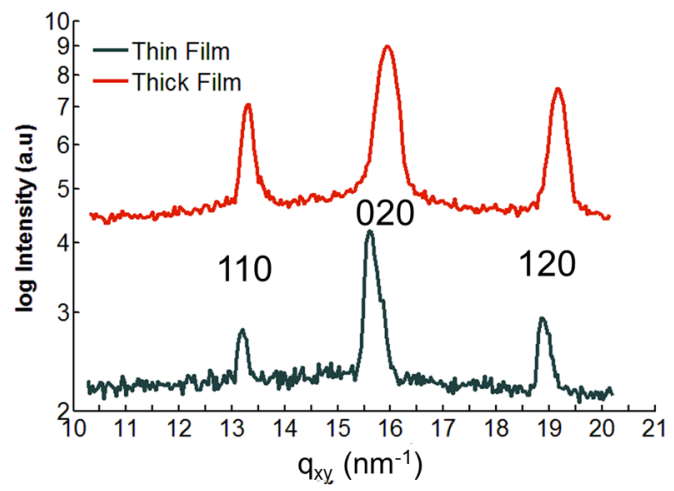

d)

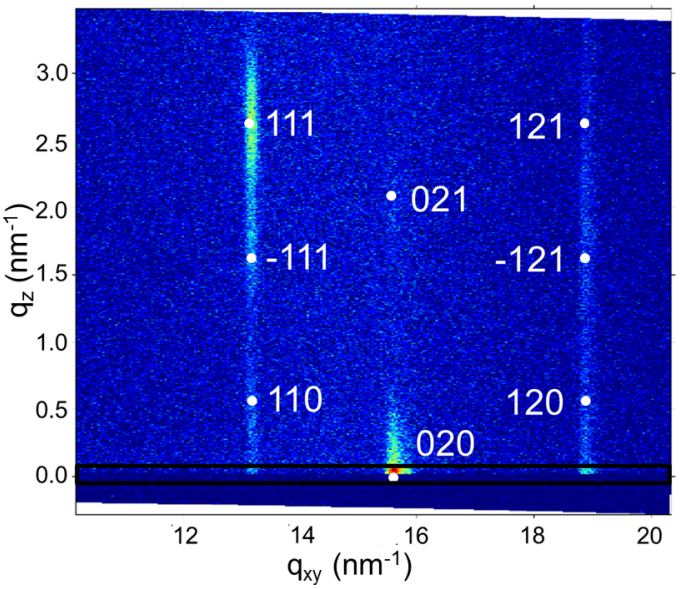

Figure 3. (a) sXRD patterns of $\mathrm{C}_{8}-\mathrm{BTBT}-\mathrm{C}_{8}$ thin films with different film thickness (from top to bottom: $85,50,35,18$, and $9 \mathrm{~nm}$ ) measured at room temperature. (b) GIXD 1D patterns (intensity as a function of $q_{x y}$ ) of two selected thin films measured at room temperature denoted as thick film (top, around $40 \mathrm{~nm}$ thick) and thin film (bottom, around $9 \mathrm{~nm}$ thick) obtained from the integration of the corresponding $2 \mathrm{D}$ images represented in (c) and (d), respectively. The $q_{z}$ range of integration is represented as a red and black rectangle in (c) and (d), respectively. Indexations of observed reflections are indicated in (b), (c), and (d) for the two thin films considered.

a)

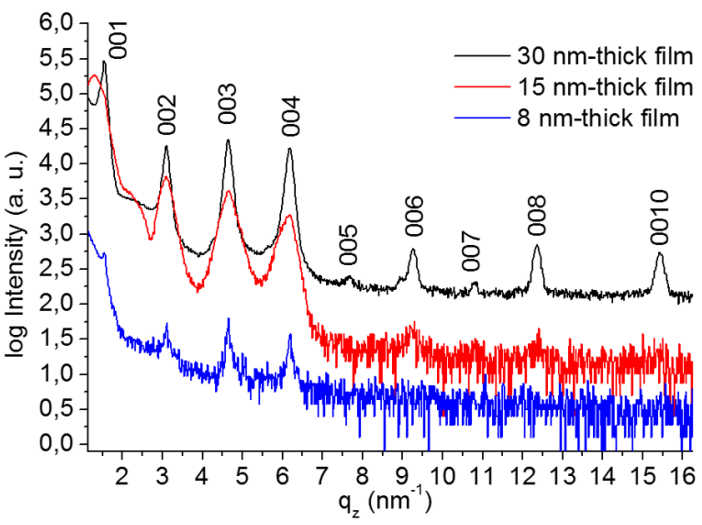

b)

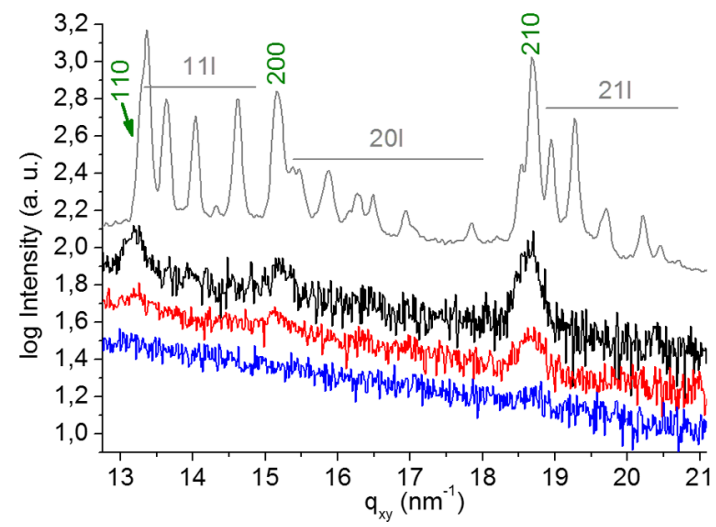

Figure 4. (a) sXRD patterns of $\mathrm{C}_{8}-\mathrm{BTBT}$ thin films with different film thickness (from top to bottom: 30,15 , and $8 \mathrm{~nm}$ ) measured at room temperature. (b) In plane GIXD patterns of the same samples (same order from top to bottom) also measured at room temperature together with the XRD pattern collected for a powder sample of $\mathrm{C}_{8}-\mathrm{BTBT}$ (in gray) as shown in Figure $2 \mathrm{~b} .11 \mathrm{l}, 20 \mathrm{l}$, and $21 \mathrm{l}$ reflections are highlighted on the latter XRD pattern showing in particular the perfect matching between the positions of 110, 200, and 210 reflections (in green) with those of the three reflections observed for the in plane GIXD scans.

Structural Characterization of $\mathrm{C}_{8}-\mathrm{BTBT}-\mathrm{C}_{8}$ and $\mathrm{C}_{8}-$ BTBT Thin Films. Thin films of the symmetrical molecule $\mathrm{C}_{8}-$ $\mathrm{BTBT}-\mathrm{C}_{8}$ were investigated by $\mathrm{XXR}$ in the thickness range from 9 to $85 \mathrm{~nm}$. The results are depicted in Figure 3a. The strongest diffraction peak is observed at $q_{z}=2.17 \mathrm{~nm}^{-1}$, and additional reflections of higher order are observed at $q_{z}$ values of 4.33 and $6.48 \mathrm{~nm}^{-1}$. All of these reflections arise from a single net plane with an interplanar distance of $2.90 \mathrm{~nm}$. Figure 
a)

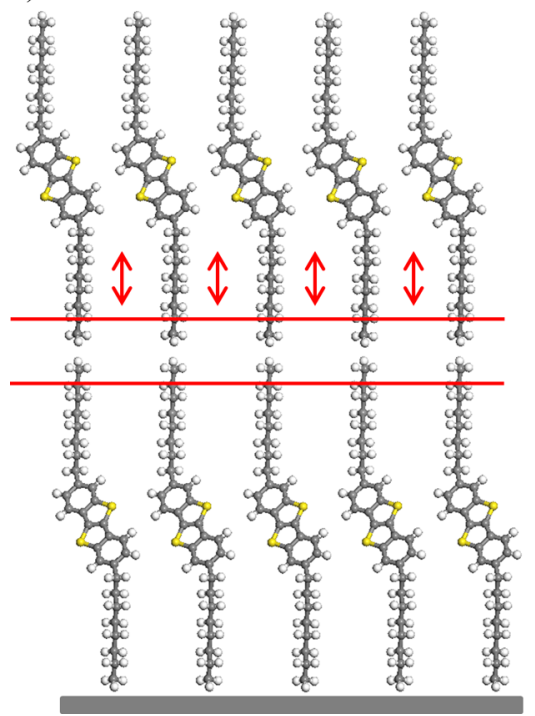

b)

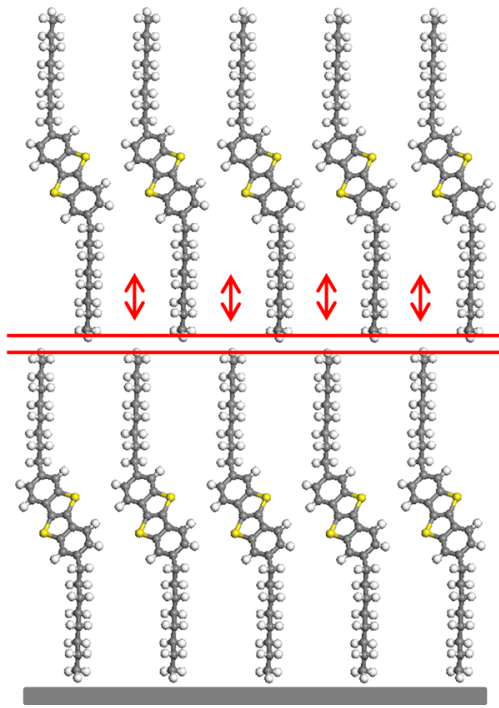

Figure 5. Schematic representations of (a) the aligned structure and (b) the shifted structure for $\mathrm{C}_{8}-\mathrm{BTBT}-\mathrm{C}_{8}$ molecules. Red arrows schematize fluctuations of the position of $\mathrm{C}_{8}-\mathrm{BTBT}-\mathrm{C}_{8}$ molecules along the molecular axis (the longer are the arrows, the larger is the effect of fluctuations), and the two horizontal red lines delimit the resulting interface between layers.

$3 \mathrm{c}$ and d gives GIXD 2D images measured for two selected thin films of rather different film thickness denoted as thick film (around $40 \mathrm{~nm}$ thick) and thin film (around $9 \mathrm{~nm}$ thick), while Figure $3 \mathrm{~b}$ shows the superimposition of the integrated intensity as a function of $q_{x y}$ of the two selected films obtained from the respective $2 \mathrm{D}$ images $\left(q_{z}\right.$ ranges of integration shown as rectangles in Figure $3 c$ and $d$ ). In both cases, three diffraction rods are clearly observed at $q_{x y}$ values of around 13.3,16.0, and $19.0 \mathrm{~nm}^{-1}$, although with much reduced intensity in the case of thin film due to the relatively lower thickness of this film as compared to thick film. Combining the results from sXRD and GIXD points to a layered herringbone structure with the herringbone layers parallel to the substrate surface. Further more, all observed diffraction peaks in SXRD as well as in GIXD can be indexed using the single crystal structure of $\mathrm{C}_{8}-\mathrm{BTBT}-$ $\mathrm{C}_{8}{ }^{31,32}$ The specular diffraction peaks correspond to the 001 reflections, while the diffraction rods revealed by GIXD measurements correspond to $11 l, 02 l$, and $12 l$ families of reflections (see Figure $3 b-d$ ). It is worth pointing out that no noticeable shift of peak position is observed for the sXRD patterns in the broad range of film thickness investigated. The only change observed is the typical peak broadening when film thickness decreases arising from the concomitant decrease of crystallite size. In the case of GIXD 1D patterns, a slight shift to lower $q_{x y}$ (so to higher distance) is however revealed for the three observed reflections when going from the thick film to the thin film. We will discuss this result later. Globally, all of these results indicate that the bulk crystal structure of $\mathrm{C}_{8}-\mathrm{BTBT}-\mathrm{C}_{8}$ is exclusively observed for all thin films down to a film thickness of around $9 \mathrm{~nm}$.

sXRD patterns of $\mathrm{C}_{8}-$ BTBT thin films $(30,15$, and $8 \mathrm{~nm}$ thick) measured at room temperature are displayed in Figure 4a. First, a strong $00 l$ texture is observed for all thin films as only $00 l$ reflections are observed in the whole diagram even in the $q$ region where intense Bragg reflections (other than $00 l$ ones) were observed for powder samples (see Figure $2 \mathrm{a}$ or $\mathrm{b}$ for comparison). As for $\mathrm{C}_{8}-\mathrm{BTBT}-\mathrm{C}_{8}$, peak width increases while film thickness decreases, yet with the exception of the $8 \mathrm{~nm}$ thick sample. This is actually due to dewetting occurring upon crystallization from the melt after the annealing procedure, then yielding small peak intensity and nonrepresentative peak width much likely due to larger crystalline domains on a reduced number of localized spots of the film. Particularly noteworthy is that the observed position of $00 \mathrm{l}$ reflections is the same as for powder samples independent of film thickness, suggesting that the same phase is exhibited in bulk as well as in thin films. This is effectively confirmed by GIXD measurements performed on the same thin film samples and shown in Figure $4 \mathrm{~b}$. Three reflections clearly emerge from the background for the 30 and $15 \mathrm{~nm}$ thick films at $13.2,15.2$, and $18.7 \mathrm{~nm}^{-1}$, while for the 8 $\mathrm{nm}$ thick film a single reflection is hardly distinguished at 18.7 $\mathrm{nm}^{-1}$. These three observed in plane reflections could unambiguously be indexed as 110, 200, and 210 reflections, respectively, using the unit cell dimensions of form III determined in Bulk Phase Behavior of C8-BTBT-C8 and C8-BTBT. Moreover, the relative intensities of these three reflections are similar to those obtained from crystal structure determination of form III (see Figures $2 b$ and $4 b$ ); thus the same crystal structure occurs in thin films as well as in bulk samples.

\section{DISCUSSION}

The results shown in the previous section all converge to a similar conclusion for the two BTBT based molecules; that is, no substrate induced phases are revealed in the range of thickness investigated. In our experiments, the minimum average film thickness considered corresponds to about 2-4 molecular layers and constitutes accordingly a lower limit of detection of a crystal arrangement close to the substrate surface by sXRD (4-5 molecular layers are at least needed to yield a detectable signal). However, GIXD measurements performed on $\mathrm{C}_{8}-\mathrm{BTBT}-\mathrm{C}_{8}$ thin film (9 nm thick sample), presented in the Results, showed that the packing arrangement of molecules in these systems corresponds to the bulk crystal structure. These results have also been confirmed by recent GIXD measurements carried out on $\mathrm{C}_{8}-\mathrm{BTBT}-\mathrm{C}_{8}$ monolayers and bilayers realized by spin coating (same deposition conditions as in this study). ${ }^{46}$ Noticeably, a slight increase of the $b$ parameter 
is pointed out when comparing the lattice constants determined for the monolayer or bilayer structures $(b=0.805 \mathrm{~nm})$ to those from the single crystal structure $(b=0.788 \mathrm{~nm})$ as illustrated by the peak shifts observed in Figure $3 b$. We attribute this effect to an increase of the area per molecule within the layers due to a significant decrease of interlayer intermolecular interactions in the case of monolayer or bilayer structures as compared to much thicker films. Besides, substrate induced phases of $\pi$ conjugated molecules are rather characterized by a decrease of the intralayer lattice constants, which accompanies the typical decrease of the tilt angle of the molecular axis toward the substrate normal witnessing enhanced substrate/molecules interactions. ${ }^{17-19}$ To summarize, the slight change of cell parameters observed for ultrathin films of $\mathrm{C}_{8}-\mathrm{BTBT}-\mathrm{C}_{8}$ rather corresponds to a relaxation of the unit cell dimensions due to such reduced film thickness while still keeping the same fractional atomic positions, and so does not account for the presence of a substrate induced polymorph. In the case of $\mathrm{C}_{8}-$ BTBT, we anticipate that the bulk crystal structure should also be present even for films with monolayer thickness given its similarity to that of $\mathrm{C}_{8}-\mathrm{BTBT}-\mathrm{C}_{8}$. Moreover, it seems unlikely that a different crystalline phase could be stabilized on only one or two layers and then the bulk crystal structure would grow on top while even for dewetted films only the presence of the bulk phase is put forward. We then postulate that no substrate induced phases are stabilized for $\mathrm{C}_{8}-\mathrm{BTBT}-\mathrm{C}_{8}$ and $\mathrm{C}_{8}-$ BTBT thin films and that the bulk phase crystallizes directly on the substrate surface during film formation when the solvent evaporates.

According to the work of Yoneya et al. on pentacene, ${ }^{22}$ the thin film phase is favored close to the substrate surface as the packing arrangement of pentacene molecules induces a flatter interface between molecular lamellae. This is practically achieved by a "shifted structure" whereby the positions of pentacene molecules of a given lamella are shifted within the ( $a$, b) plane (contact plane of the lamellae) with respect to pentacene molecules of the subsequent lamella. This particular packing arrangement has been proved to effectively reduce position fluctuations of pentacene molecules between the lamellae, thus reducing the size of the interface between them, contrary to the "aligned structure", which in turn appears to be the bulk most stable phase of pentacene. ${ }^{22}$ Those two types of structure are schematically represented in Figure 5 for $\mathrm{C}_{8}-$ $\mathrm{BTBT}-\mathrm{C}_{8}$ molecules. In the aligned structure (Figure $5 \mathrm{a}$ ), position fluctuations along the molecular axis (symbolized by red double arrows) would result in a less defined interface between the molecular layers as the translation of one molecule would induce the translation of the molecule situated just above in the next layer. In the shifted structure (Figure 5b), the stronger interactions between molecules of subsequent layers reduce the effects of molecular position fluctuations, thus implying a much defined interface between the layers.

In the case of $\mathrm{C}_{8}-\mathrm{BTBT}-\mathrm{C}_{8}$, the contacts between lamellae are exclusively achieved by alkyl chains and actually agree with a "shifted structure" as shown in Figure 6 displaying the packing arrangement of $\mathrm{C}_{8}-\mathrm{BTBT}-\mathrm{C}_{8}$ molecules at the interface between two superimposed lamellae in the known bulk crystal structure. In the case of $\mathrm{C}_{8}-\mathrm{BTBT}$ crystal structure, both BTBT core-BTBT core and octyl chain-octyl chain interfaces are present, and both also effectively exhibit the above mentioned shifted arrangement as shown in Figure 7. Hence, these findings strengthen the idea that substrate induced phases may be surface selected polymorphs that can be stabilized only a)

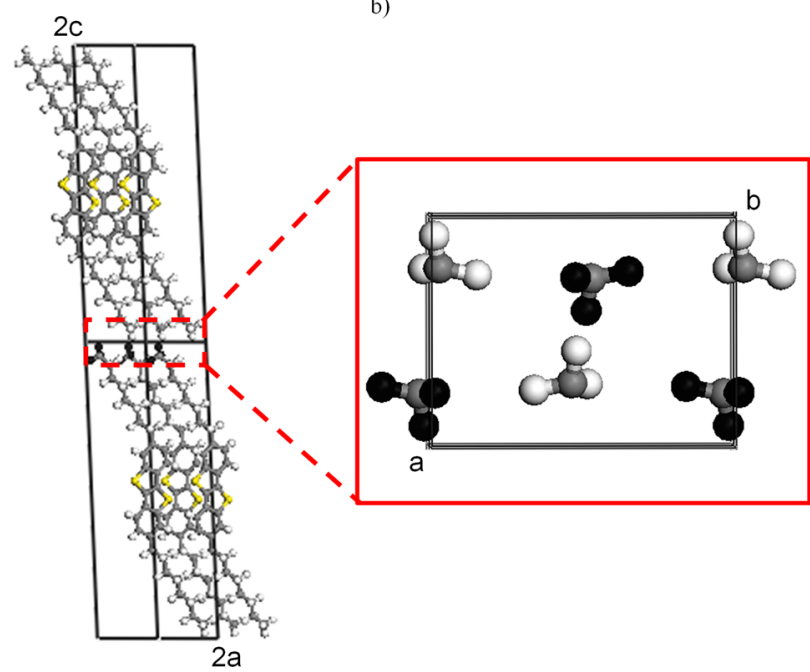

Figure 6. Views of the crystal structure of $\mathrm{C}_{8}-\mathrm{BTBT}-\mathrm{C}_{8}{ }^{31,32}$ emphasizing the packing arrangement of $\mathrm{C}_{8}-\mathrm{BTBT}-\mathrm{C}_{8}$ molecules at the interface between two superimposed lamellae $(a)$ in the $(a, c)$ plane (side view) and (b) in the $(a, b)$ plane (top view) showing only the packing of methyl groups at the interface for the sake of clarity.

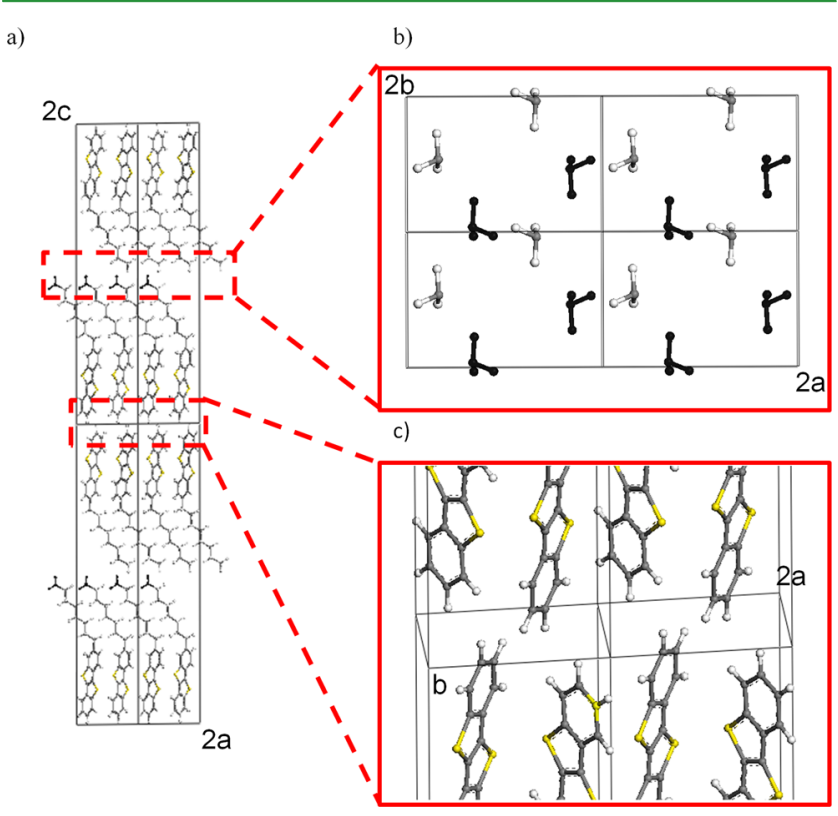

Figure 7. Views of the crystal structure of $\mathrm{C}_{8}-\mathrm{BTBT}$ emphasizing the packing arrangement of $\mathrm{C}_{8}-\mathrm{BTBT}$ molecules at the interface between superimposed bilayers $(a)$ in the $(a, c)$ plane (side view) and $(b, c)$ in the $(a, b)$ plane showing the packing of (b) methyl groups (top view) and (c) BTBT cores at the interfaces.

in the vicinity of the underlying substrate as proposed by previous studies. ${ }^{18,22}$ Noticeably, in the present particular case of alkylated BTBTs, it appears that the equilibrium stable bulk phase is also the one favored in thin films close to the substrate surface. This is an important result as the presence of substrate induced phases is a quite commonly observed phenomenon for conjugated molecules, so that its nonobservation can be judged as an exception and even might be a reason for the unprecedented charge transport properties pointed out for this family of compounds. Indeed, the presence of a substrate induced phase with probably less efficient packing arrangement of conjugated cores would lead to a decrease of charge 
transport and consequently worse device performances. ${ }^{8,26}$ Last, it is important to notice that the results obtained in this Article concern thin films deposited on oxidized silicon wafers, which are typically used as dielectric layers in real electronic devices. However, it could be interesting to see whether the observations made herein would still hold for other substrates such as $\mathrm{Al}$ or $\mathrm{Au}$ (used as electrodes in devices) especially knowing that interdiffusion between metal and organic layers has been revealed for those metals on length scales comparable to $2-3 \mathrm{C}_{8}-\mathrm{BTBT}-\mathrm{C}_{8}$ layers, as shown by recent studies. ${ }^{47,48}$ Effects of the substrate on the crystal structure of the deposited film will be the subject of future works.

\section{CONCLUSION}

The bulk phase behavior of symmetrically $\left(\mathrm{C}_{8}-\mathrm{BTBT}-\mathrm{C}_{8}\right)$ and asymmetrically $\left(\mathrm{C}_{8}-\mathrm{BTBT}\right)$ alkylated benzthieno[1] benzothieno[3,2 $b]$ benzothiophene molecules has been inves tigated. In particular, the crystal structure of the room temperature phase of $\mathrm{C}_{8}-\mathrm{BTBT}$ (form III) has been determined from powder $\mathrm{X}$ ray diffraction data. It appeared that this crystal phase is quite similar to that exhibited by $\mathrm{C}_{8}-$ $\mathrm{BTBT}-\mathrm{C}_{8}$, the main difference between both being the presence of bilayers composed of head to head (or tail to tail) stacked molecules. Thin films of the two compounds have been fabricated and characterized by specular $\mathrm{X}$ ray diffraction and grazing incidence $\mathrm{X}$ ray diffraction. It was found for both compounds that the herringbone layers crystallize parallel to the substrate surface so that the aromatic BTBT units are approximately perpendicular to the substrate surface. Moreover, in both cases, the bulk phase is present even for ultrathin films. This gives strong evidence that the bulk phase might crystallize close to the substrate surface and grow up to the whole film thickness during film formation.

\section{AUTHOR INFORMATION}

\section{Corresponding Author}

*Tel.: +33235522430. Fax: +33235522927. E mail: gabin. gbabode@univ rouen.fr.

\section{Present Address}

${ }^{\perp}$ Normandie Université, Unité de Cristallogénèse, SMS EA 3233, Université de Rouen, 1 rue Lucien Tesnière, F 76821 Mont Saint Aignan Cedex, France.

\section{Notes}

The authors declare no competing financial interest.

\section{ACKNOWLEDGMENTS}

We acknowledge financial support from the ARC program of the Communauté Française de Belgique (Grant no. 20061) and from the Walloon Region (WCS project no. 1117306).

\section{REFERENCES}

(1) O’Neill, M.; Kelly, S. M. Liquid Crystals for Charge Transport, Luminescence, and Photonics. Adv. Mater. 2003, 15, 1135-1146.

(2) Facchetti, A. Semiconductors for Organic Transistors. Mater. Today 2007, 10, 28-37.
(3) Arias, A. C.; MacKenzie, J. D.; McCulloch, I.; Rivnay, J.; Salleo, A. Materials and Applications for Large Area Electronics: Solution Based Approaches. Chem. Rev. 2010, 110, 3-24.

(4) Gelinck, G.; Heremans, P.; Nomoto, K.; Anthopoulos, T. D. Organic Transistors in Optical Displays and Microelectronic Applications. Adv. Mater. 2010, 22, 3778-3798.

(5) Guo, Y.; Yu, G.; Liu, Y. Functional Organic Field Effect Transistors. Adv. Mater. 2010, 22, 4427-4447.

(6) Dinelli, F.; Murgia, M.; Levy, P.; Cavallini, M.; Biscarini, F.; de Leeuw, D. M. Spatially Correlated Charge Transport in Organic Thin Film Transistors. Phys. Rev. Lett. 2004, 92, 116802.

(7) Coropceanu, V.; Cornil, J.; da Silva Filho, D. A.; Olivier, Y.; Silbey, R.; Bredas, J. L. Charge Transport in Organic Semiconductors. Chem. Rev. 2007, 107, 926-952.

(8) Jurchescu, O. D.; Mourey, D. A.; Subramanian, S.; Parkin, S. R.; Vogel, B. M.; Anthony, J. E.; Jackson, T. N.; Gundlach, D. J. Effects of Polymorphism on Charge Transport in Organic Semiconductors. Phys. Rev. B 2009, 80, 085201.

(9) Wang, C.; Dong, H.; Hu, W.; Liu, Y.; Zhu, D. Semiconducting $\pi$ Conjugated Systems in Field Effect Transistors: A Material Odyssey of Organic Electronics. Chem. Rev. 2012, 112, 2208-2267.

(10) Chou, W. Y.; Chang, M. H.; Cheng, H. L.; Lee, Y. C.; Chang, C. C.; Sheu, H.S. New Pentacene Crystalline Phase Induced by Nanoimprinted Polyimide Gratings. J. Phys. Chem. C 2012, 116, 8619-8626.

(11) Bouchoms, I. P. M.; Schoonveld, W. A.; Vrijmoeth, J.; Klapwijk, T. M. Morphology Identification of the Thin Film Phases of Vacuum Evaporated Pentacene on $\mathrm{SiO}_{2}$ Substrates. Synth. Met. 1999, 104, 175-178.

(12) Mattheus, C. C.; Dros, A. B.; Baas, J.; Oostergetel, G. T.; Meetsma, A.; de Boer, J. L.; Palstra, T. T. M. Identification of Polymorphs of Pentacene. Synth. Met. 2003, 138, 475-481.

(13) Nabok, D.; Puschnig, P.; Ambrosch Draxl, C.; Werzer, O.; Resel, R.; Smilgies, D. M. Crystal and Electronic Structures of Pentacene Thin Films From Grazing Incidence X ray Diffraction and First Principles Calculations. Phys. Rev. B 2007, 76, 235322.

(14) Yoshida, H.; Inaba, K.; Sato, N. X ray Diffraction Reciprocal Space Mapping Study of the Thin Film Phase of Pentacene. Appl. Phys. Lett. 2007, 90, 181930.

(15) Schiefer, S.; Huth, M.; Dobrinevski, A.; Nickel, B. Determi nation of the Crystal Structure of Substrate Induced Pentacene Polymorphs in Fiber Structured Thin Films. J. Am. Chem. Soc. 2007, 129, 10316-10317.

(16) Yoshida, H.; Sato, N. Crystallographic and Electronic Structures of Three Different Polymorphs of Pentacene. Phys. Rev. B 2008, 77, 235205.

(17) Mannsfeld, S. C. B.; Virkar, A.; Reese, C.; Toney, M. F.; Bao, Z. Precise Structure of Pentacene Monolayers on Amorphous Silicon Oxide and Relation to Charge Transport. Adv. Mater. 2009, 21, 22942298.

(18) Drummy, L. F.; Martin, D. C. Thickness Driven Orthorhombic to Triclinic Phase Transformation in Pentacene Thin Films. Adv. Mater. 2005, 17, 903-907.

(19) Cheng, H. L.; Mai, Y. S.; Chou, W. Y.; Chang, L. R.; Liang, X. W. Thickness Dependent Structural Evolutions and Growth Models in Relation to Carrier Transport Properties in Polycrystalline Pentacene Thin Films. Adv. Funct. Mater. 2007, 17, 3639-3649.

(20) Della Valle, R. G.; Venuti, E.; Brillante, A.; Girlando, A. Molecular Dynamics Simulations for a Pentacene Monolayer on Amorphous Silica. ChemPhysChem 2009, 10, 1783-1788.

(21) Viani, L.; Risko, C.; Toney, M. F.; Breiby, D. W.; Brédas, J. L. Substrate Induced Variations of Molecular Packing, Dynamics, and Intermolecular Electronic Couplings in Pentacene Monolayers on the Amorphous Silica Dielectric. ACS Nano 2013, 8, 690-700.

(22) Yoneya, M.; Kawasaki, M.; Ando, M. Molecular Dynamics Simulations of Pentacene Thin Films: The Effect of Surface on Polymorph Selection. J. Mater. Chem. 2010, 20, 10397-10402. 
(23) Yoneya, M.; Kawasaki, M.; Ando, M. Are Pentacene Monolayer and Thin Film Polymorphs Really Substrate Induced? A Molecular Dynamics Simulation Study. J. Phys. Chem. C 2012, 116, 791-795.

(24) Wedl, B.; Resel, R.; Leising, G.; Kunert, B.; Salzmann, I.; Oehzelt, M.; Koch, N.; Vollmer, A.; Duhm, S.; Werzer, O.; Gbabode, G.; Sferrazza, M.; Geerts, Y. Crystallisation Kinetics in Thin Films of Dihexyl Terthiophene: the Appearance of Polymorphic Phases. RSC Adv. 2012, 2, 4404-4414.

(25) Lercher, C.; Resel, R.; Balandier, J. Y.; Niebel, C.; Geerts, Y. H.; Sferrazza, M.; Gbabode, G. Effects of Temperature on the Poly morphism of $\alpha, \omega$ Dioctylterthiophene in Thin Films. J. Cryst. Growth 2014, 386, 128-134.

(26) Giri, G.; Verploegen, E.; Mannsfeld, S. C. B.; Atahan Evrenk, S.; Kim, D. H.; Lee, S. Y.; Becerril, H. A.; Aspuru Guzik, A.; Toney, M. F.; Bao, Z. Tuning Charge Transport in Solution Sheared Organic Semiconductors Using Lattice Strain. Nature 2011, 480, 504-508.

(27) Salzmann, I.; Nabok, D.; Oehzelt, M.; Duhm, S.; Moser, A.; Heimel, G.; Puschnig, P.; Ambrosch Draxl, C.; Rabe, J. P.; Koch, N. Structure Solution of the 6,13 Pentacenequinone Surface Induced Polymorph by Combining $\mathrm{X}$ ray Diffraction Reciprocal Space Mapping and Theoretical Structure Modeling. Cryst. Growth Des. 2011, 11, 600-606.

(28) Gbabode, G.; Dumont, N.; Quist, F.; Schweicher, G.; Moser, A.; Viville, P.; Lazzaroni, R; Geerts, Y. H. Substrate Induced Crystal Plastic Phase of a Discotic Liquid Crystal. Adv. Mater. 2012, 24, 658662.

(29) Chattopadhyay, B.; Ruzié, C.; Resel, R.; Geerts, Y. H. Substrate Induced Phases: Transition From a Liquid Crystalline to a Plastic Crystalline Phase via Nucleation Initiated by the Substrate. Liq. Cryst. 2013, 1-8.

(30) Werzer, O.; Boucher, N.; de Silva, J. P.; Gbabode, G.; Geerts, Y. H.; Konovalov, O.; Moser, A.; Novak, J.; Resel, R.; Sferrazza, M. Interface Induced Crystal Structures of Dioctyl Terthiophene Thin Films. Langmuir 2012, 28, 8530-8536.

(31) Ebata, H.; Izawa, T.; Miyazaki, E.; Takimiya, K.; Ikeda, M.; Kuwabara, H.; Yui, T. Highly Soluble [1]Benzothieno[3,2 b] benzothiophene (BTBT) Derivatives for High Performance, Solu tion Processed Organic Field Effect Transistors. J. Am. Chem. Soc. 2007, 129, 15732-15733.

(32) Izawa, T.; Miyazaki, E.; Takimiya, K. Molecular Ordering of High Performance Soluble Molecular Semiconductors and Re evaluation of Their Field Effect Transistor Characteristics. Adv. Mater. 2008, 20, 3388-3392.

(33) Liu, C.; Minari, T.; Lu, X.; Kumatani, A.; Takimiya, K.; Tsukagoshi, K. Solution Processable Organic Single Crystals with Bandlike Transport in Field Effect Transistors. Adv. Mater. 2011, 23, 523-526.

(34) Minemawari, H.; Yamada, T.; Matsui, H.; Tsutsumi, J. y.; Haas, S.; Chiba, R.; Kumai, R.; Hasegawa, T. Inkjet Printing of Single Crystal Films. Nature 2011, 475, 364-367.

(35) Amin, A. Y.; Reuter, K.; Meyer Friedrichsen, T.; Halik, M. Interface Engineering in High Performance Low Voltage Organic Thin Film Transistors Based on 2,7 Dialkyl [1] benzothieno[3,2 b] [1] benzothiophenes. Langmuir 2011, 27, 15340-15344.

(36) Amin, A. Y.; Khassanov, A.; Reuter, K.; Meyer Friedrichsen, T.; Halik, M. Low Voltage Organic Field Effect Transistors with a 2 Tridecyl[1] benzothieno[3,2 b][1] benzothiophene Semiconductor Layer. J. Am. Chem. Soc. 2012, 134, 16548-16550.

(37) Grigoriadis, C.; Niebel, C.; Ruzié, C.; Geerts, Y. H.; Floudas, G. Order, Viscoelastic, and Dielectric Properties of Symmetric and Asymmetric Alkyl[1]benzothieno[3,2 b][1] benzothiophenes. J. Phys. Chem. B 2014, 118, 1443-1451.

(38) Košata, B.; Kozmik, V.; Svoboda, J.; Novotná, V.; Vaněk, P.; Glogarová, M. Novel Liquid Crystals Based on [1]Benzothieno[3,2 b] [1]benzothiophene. Liq. Cryst. 2003, 30, 603-610.

(39) Evain, M.; Deniard, P.; Jouanneaux, A.; Brec, R. Potential of the INEL X ray Position Sensitive Detector: a General Study of the Debye Scherrer Setting. J. Appl. Crystallogr. 1993, 26, 563-569.
(40) Huang, T. C.; Toraya, H.; Blanton, T. N.; Wu, Y. X ray Powder Diffraction Analysis of Silver Behenate, a Possible Low Angle Diffraction Standard. J. Appl. Crystallogr. 1993, 26, 180-184.

(41) Kobayashi, N.; Ogata, H.; Nonaka, N.; Luk'yanets, E. A. Effect of Peripheral Substitution on the Electronic Absorption and Fluorescence Spectra of Metal Free and Zinc Phthalocyanines. Chem.-Eur. J. 2003, 9, 5123-5134.

(42) Neumann, M. A. X Cell: a Novel Indexing Algorithm for Routine Tasks and Difficult Cases. J. Appl. Crystallogr. 2003, 36, 356365 .

(43) Pawley, G. S. Unit cell Refinement from Powder Diffraction Scans. J. Appl. Crystallogr. 1981, 14, 357-361.

(44) Engel, G. E.; Wilke, S.; König, O.; Harris, K. D. M.; Leusen, F. J. J. PowderSolve A Complete Package for Crystal Structure Solution from Powder Diffraction Patterns. J. Appl. Crystallogr. 1999, 32, 11691179.

(45) Mayo, S. L.; Olafson, B. D.; Goddard, W. A., III. DREIDING: a Generic Force Field for Molecular Simulations. J. Phys. Chem. 1990, 94, 8897-8909.

(46) Dohr, M.; Werzer, O.; Shen, Q.; Salzmann, I.; Teichert, C.; Ruzié, C.; Schweicher, G.; Geerts, Y. H.; Sferrazza, M.; Resel, R. Dynamics of Monolayer-Island Transitions in 2,7 Dioctyl benzothie nobenzthiophene Thin Films. ChemPhysChem 2013, 14, 2554-2559.

(47) Perlich, J.; Memesa, M.; Diethert, A.; Metwalli, E.; Wang, W.; Roth, S. V.; Timmann, A.; Gutmann, J. S.; Müller Buschbaum, P. Preservation of the Morphology of a Self Encapsulated Thin Titania Film in a Functional Multilayer Stack: An X Ray Scattering Study. ChemPhysChem 2009, 10, 799-805.

(48) Yu, S.; Santoro, G.; Sarkar, K.; Dicke, B.; Wessels, P.; Bommel, S.; Döhrmann, R.; Perlich, J.; Kuhlmann, M.; Metwalli, E.; Risch, J. F. H.; Schwartzkopf, M.; Drescher, M.; Müller Buschbaum, P.; Roth, S. V. Formation of Al Nanostructures on Alq3: An in Situ Grazing Incidence Small Angle X ray Scattering Study during Radio Frequency Sputter Deposition. J. Phys. Chem. Lett. 2013, 4, 3170-3175. 